\title{
Glycemic Response and Glycemic Index of Common Sweeteners and Honey Incorporated Products
}

\author{
Seema Rana ${ }^{1}$, Shweta Sharma ${ }^{2}$, Charu Katare ${ }^{3}$, Veena Shrivatava ${ }^{4}$, GBKS \\ Prasad $^{5}$ \\ ${ }^{1-4}$ Department of Home Science, Govt. KRG PG Autonomous College, Gwalior, Madhya Pradesh, India. \\ ${ }^{5}$ School of Studies in Biotechnology, Jiwaji University, Gwalior, Madhya Pradesh, India.
}

\begin{abstract}
Honey is the sweet and viscous product, produced by the honeybee from the nectar of plants. Honey is composed mainly of carbohydrates, lesser amounts of water and a great number of minor components. Sugars are the main constituents of honey, most important sugars are the monosaccharides hexoses, fructose and glucose, which are products of the hydrolysis of the disaccharide sucrose. Honey is considered a valuable medicinal food in Indian system of medicine and is found to be useful in management of diabetes. Honey is a powerful antioxidant and used in the day to day life as natural sweetener. The study was conducted to determine the glycemic index (GI) of products made with different natural sweeteners. Normal healthy subjects $(n=9)$ and impaired glucose tolerant (IGT) subjects (n=9) were included in the study. Blood glucose curves at 0, 30, 60, 90 $\& 120$ minutes indicated significant difference in incremental area under the curve (IAUC) of glucose and nutribar made with different sweeteners in subjects with IGT as well as in normal healthy subjects. The mean IAUC of nutribar was significantly lower $(p=<0.01)$ than that of glucose in subjects with IGT as well as in normal healthy subjects.
\end{abstract}

Keywords: Natural sweeteners, diabetes, glycemic response (GR), glycemic index (GI).

\section{Introduction}

The impact of carbohydrates on human health is discussed controversially, especially the understanding of how the carbohydrates of a given food affect the blood glucose level. The major dietary component responsible for fluctuations in blood glucose levels is carbohydrate (Jenkins DJ et al., 1981 \& Gannon MC et al., 1989). Both the amount and the source of carbohydrate appear to have profound influence on postprandial glucose levels (Brand JC et al., 1985).

The glycemic response is a measure of the impact of a food on blood glucose value. Foods with faster rates of digestion and absorption of carbohydrates cause blood glucose levels to increase resulting highest glycemic response (GR) in comparison to those with lower GR in which glucose is released slowly into blood and is important in the control of diabetes (Hubrich, RD et al.,2006).

Sugar, Jaggery and honey are traditional sweeteners, Honey a wonderfully rich golden liquid is a naturally delicious, sweet and viscous product. The traditional use of honey in food preparations has been substituted in most cases by sugar and more recently by various sugar syrups derived from starches. At the same time, as part of the increasing appreciation of more natural products in many countries, honey has been "rediscovered" as a valuable food. It contains up to $38.2 \%$ fructose, $31.3 \%$ glucose, $0.7 \%$ sucrose \& other nutrients approximately 25\% (Bogdanov et al., 1995, Lipp et al., 1994, White J W 1975 \& ANON 1995).

Jaggery is a concentrated product of cane juice without separation of the molasses and crystals and can vary from golden brown to dark brown in color. It contains up to 50\% sucrose, up to $20 \%$ invert sugars with some other insoluble matter such as ash, proteins and bagasse fibers (Ghosh, A.K et al 1983). It is directly consumed by human and used in animal feed mixtures. Jaggery is often called the medicinal sugar and possesses nutritive properties of high order. The study was undertaken to evaluate glycemic response, determine the glycemic index (GI) and acceptability of the products made with different natural sweeteners so that their beneficial effect from GI point of view may be understood.

\section{Material And Method}

Nutribar was prepared with wheat flour, milk powder and ground nuts and different natural sweetners like honey, cane sugar and jiggery were used for sweet taste. All the three combinations of Nutribar i.e NH (Nutribar prepared with Honey), NCS (Nutribar prepared with cane sugar) and NJ (Nutribar prepared with jaggery) were subjected to organoleptic evaluation for various attributes like appearance, texture, colour, flavour and softness. A 9 point hedonic scale determined organoleptic qualities of various combinations of nutribar. 


\section{II.1 Sensory evaluation of different type of nutribar}

The nutribar thus prepared were tested by the panel of 7 judges for its organoleptic quality and acceptability. Distinct code was allotted to the products. The judges were requested to taste the nutribar and award a score with reference to a number of attributes viz. appearance, texture, colour, flavour and softness during the tasting session and scores were obtained for various organoleptic qualities. This procedure was repeated two more times. The judges who gave the similar scores in both replications were considered acceptable.

Sensory evaluation or the organoleptic quality of nutribar was on the basis of 9-point Hedonic scale

\begin{tabular}{|l|l|}
\hline Grade & Score \\
\hline Like extremely & 9 \\
\hline Like very much & 8 \\
\hline Like moderately & 7 \\
\hline Like slightly & 6 \\
\hline Neither like nor dislike & 5 \\
\hline Dislike slightly & 4 \\
\hline Dislike moderately & 3 \\
\hline Dislike very much & 2 \\
\hline Dislike extremely & 1 \\
\hline
\end{tabular}

\section{II.2 Collection of baseline data \& determination of glycemic index}

18 subjects (9 IGT \& 9 normal healthy subjects) were selected for the study. All subjects were in the age group of 40-60 years. The subjects were explained the study protocol and a written consent for voluntary participation was obtained. Subjects were asked to attend the testing session after a 10-12 hour overnight fast on the day test was performed, having been instructed not to consume unusually large meals, drink alcohol or exercise vigorously on the previous day, and to avoid cycling or walking to the laboratory. On the first day subjects were given the standard or reference carbohydrate i.e. 25g glucose dissolved in $150 \mathrm{ml}$ of water. Blood glucose level was measured in capillary whole blood obtained by finger prick (Accu-Chek Roche Diagnostics India Pvt Ltd, Mumbai) in the fasted state at 0 and after 30, 60, 90 and 120 minutes on consumption of the reference (glucose) food. Blood glucose curves were constructed and the incremental area under the curve (IAUC) was calculated for reference food (glucose) by the trapezoidal rule (Gibaldi.M and D.Perrier., 1982) Similar procedure was repeated with test food (Nutribar).The nutribar in different combinations (25gms carbohydrates) were given during testing sessions against the standard or reference carbohydrate on the following three consecutive days at fasted state. Equicarbohydrate portion of honey (31.5gms), cane sugar (25.1gms) \& jaggery (26.3gms) was incorporated in nutribar which was calculated on the basis of carbohydrate content given in Nutritive value of Indian foods (C. Gopalan, 2004). These products were administered as test food.

\section{II.3 Calculation of Glycemic Index}

The Glycemic Index (GI) values were calculated by the method of Wolever et al., 1990. The glycemic index was calculated by dividing the IAUC for the test food by the IAUC for the reference food and multiplying by 100 for each individual. The following formula was used:

$$
\mathrm{GI}=\frac{\text { IAUC for tested Food }}{-\mathrm{IAUC} \text { for Reference Food }}
$$

IAUC - Incremental Area Under the blood glucose response Curve. individuals.

The final glycemic index for each test food was calculated as the mean of the respective GI's of the ten

\section{II.4 Statistical analysis}

Statistical analysis was performed by using a Paired t test significance level of $\mathrm{P}<0.05$. Statistics was performed by Sigma stats software package (3.5). 


\section{Tables \& Figures}

After carrying out the sensory evaluation of nutribar prepared with different sweeteners the scores awarded by the judges were tabulated.

Table -1 Sensory evaluation of nutribar

\begin{tabular}{|c|l|l|c|c|c|c|c|}
\hline $\begin{array}{c}\text { S.N } \\
\text { o. }\end{array}$ & $\begin{array}{l}\text { Combinati } \\
\text { on }\end{array}$ & $\begin{array}{l}\text { Appearan } \\
\text { ce }\end{array}$ & $\begin{array}{l}\text { Textu } \\
\text { re }\end{array}$ & $\begin{array}{l}\text { Colou } \\
\text { r }\end{array}$ & $\begin{array}{l}\text { Flavo } \\
\text { ur }\end{array}$ & $\begin{array}{l}\text { Softnes } \\
\text { s }\end{array}$ & $\begin{array}{c}\text { Overall } \\
\text { acceptability }\end{array}$ \\
\hline 1 & N H & 8 & 8 & 8 & 8 & 8 & 9 \\
\hline 2 & N C S & 8 & 8 & 8 & 8 & 8 & 9 \\
\hline 3 & N J & 8 & 8 & 8 & 8 & 8 & 9 \\
\hline
\end{tabular}

Table -2 Blood glucose response in subjects with IGT administered with nutribar varieties

\begin{tabular}{|c|c|c|c|c|c|}
\hline Test \& reference foods & \multicolumn{5}{|c|}{ Time intervals } \\
\cline { 2 - 6 } & 0 minute & $\mathbf{3 0}$ minute & $\mathbf{6 0}$ minute & $\mathbf{9 0}$ minute & $\mathbf{1 2 0}$ minute \\
\hline Glucose & 120.3 & 184.6 & 198.3 & 161.9 & 135.3 \\
\hline N H & 114.4 & 136.1 & 147.9 & 122.7 & 113.0 \\
\hline N C S & 114.9 & 145.9 & 155.6 & 139.3 & 122.1 \\
\hline N J & 115.9 & 141.1 & 148.7 & 136.4 & 122.6 \\
\hline \multicolumn{7}{|c|}{ Values given mg/dl } \\
\hline
\end{tabular}

Table -3 Blood glucose response in normal healthy subjects administered with nutribar varieties

\begin{tabular}{|c|c|c|c|c|c|}
\hline \multirow{2}{*}{$\begin{array}{c}\text { Test \& reference } \\
\text { foods }\end{array}$} & \multicolumn{5}{|c|}{ Time intervals } \\
\cline { 2 - 6 } & $\begin{array}{c}\mathbf{0} \\
\text { minute }\end{array}$ & $\begin{array}{c}\mathbf{3 0} \\
\text { minute }\end{array}$ & $\mathbf{6 0}$ minute & 90 minute & 120 minute \\
\hline Glucose & 97.4 & 162.8 & 137.1 & 98.4 & 88.0 \\
\hline N H & 95.1 & 117.0 & 104.8 & 97.8 & 92.3 \\
\hline N C S & 95.8 & 126.2 & 117.7 & 109.6 & 100.9 \\
\hline N J & 97.0 & 126.6 & 119.0 & 108.3 & 101.1 \\
\hline
\end{tabular}

Table - 4 IAUC \& GI in subjects with IGT \& normal healthy subjects

\begin{tabular}{|c|c|c|l|l|l|}
\hline \multicolumn{2}{|c|}{} & \multicolumn{2}{c|}{ IAUC } & \multicolumn{2}{c|}{ GI } \\
\hline S.No. & Products & \multicolumn{1}{|c|}{ IGT } & Normal & \multicolumn{1}{c|}{ IGT } & Normal \\
\hline 1 & Glucose & 319.16 & 175.91 & - & - \\
\hline 2 & N H & $104.25^{* *}$ & $57.08^{* *}$ & 32.66 & 32.44 \\
\hline 3 & N C S & $165.83^{*}$ & 114.16 & 51.95 & 64.89 \\
\hline 4 & N J & $137.50^{* *}$ & $108.33^{*}$ & 43.08 & 61.58 \\
\hline
\end{tabular}

Values are given in $\mathrm{mg} / \mathrm{dl}$ (mean)

** Significant change $\mathrm{P}<0.01$

* Significant change $\mathrm{P}<0.05$

Table-5 Mean (\%) reduction in IAUC of nutribar varieties compared with IAUC of glucose

\begin{tabular}{|c|c|c|}
\hline \multicolumn{3}{|c|}{ \% Reduction compared to glucose } \\
\hline & IGT & Normal healthy subjects \\
\hline Nutribar Honey & 67.34 & 67.55 \\
\hline Nutribar Cane Sugar & 48.04 & 35.10 \\
\hline Nutribar Jaggery & 56.92 & 38.42 \\
\hline
\end{tabular}

Values given $\mathrm{mg} / \mathrm{dl}$

Fig 1 Blood glucose curve in subjects with IGT 


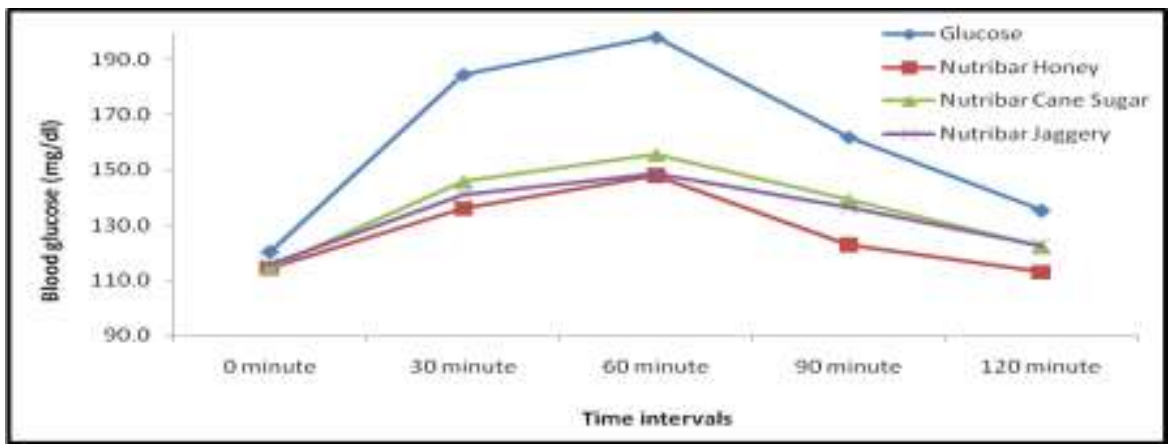

Fig 2 Blood glucose curve in normal healthy subjects

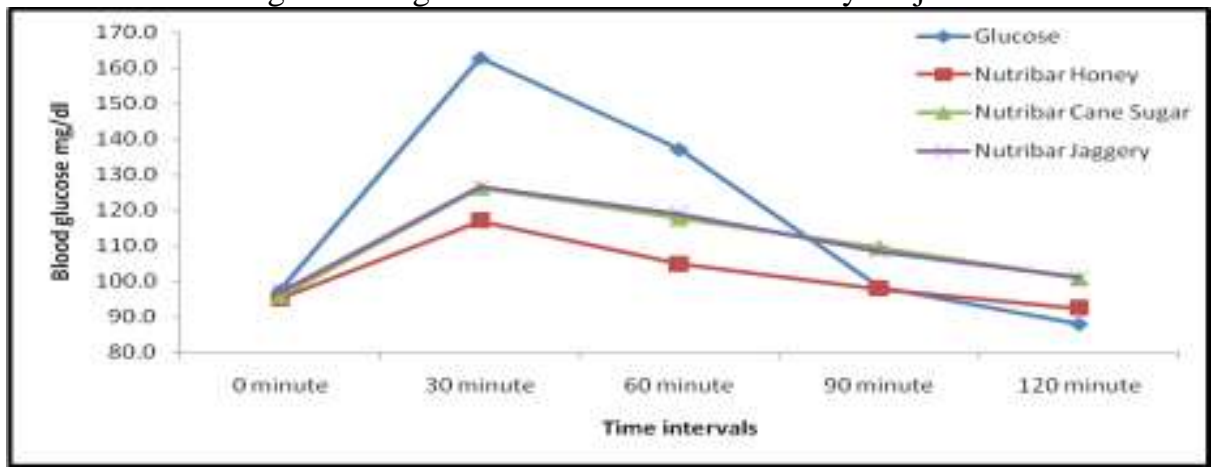

IV. Results

The mean plasma glucose responses after the consumption of glucose and the test foods in subjects with IGT are shown in Table 2. The mean IAUC of glucose was $319.16 \mathrm{mg} / \mathrm{dl}$ followed by $104.25 \mathrm{mg} / \mathrm{dl}$, $165.83 \mathrm{mg} / \mathrm{dl}$ and $137.50 \mathrm{mg} / \mathrm{dl}$ IAUC of NH, NCS \& NJ. The mean IAUC of all the variety of nutribar was significantly lower than glucose but a highly significant reduction $(\mathrm{p}=<0.005)$ was noted in case of $\mathrm{NH}$. The mean \% reduction in IAUC of all the varieties of nutribar was compared with glucose. It was observed that maximum reduction $(67.34 \%)$ in IAUC was exhibited by $\mathrm{NH}$

The mean plasma glucose responses after the consumption of glucose and the test foods in normal healthy subjects are shown in Table 3. The mean IAUC of glucose was $175.91 \mathrm{mg} / \mathrm{dl}$ followed by $57.08 \mathrm{mg} / \mathrm{dl}$, $114.16 \mathrm{mg} / \mathrm{dl} \& 108.33 \mathrm{mg} / \mathrm{dl}$ IAUC of NH, NCS and NJ. The mean IAUC of all the variety of nutribar was considerably lower than glucose but highly significant reduction $(\mathrm{p}=<0.002)$ was noted in case of $\mathrm{NH}$. The mean $\%$ reduction in IAUC of all the varieties nutribar was compared with glucose. It was observed that maximum reduction $(67.55 \%)$ in IAUC was exhibited by $\mathrm{NH}$.

GI of nutribar was calculated and it was noted that GI of NH, NCS and NJ was 32.66, 51.95 and 43.08 respectively in subjects with IGT. Similarly the mean GI of NH was 32.44 and that of NCS and NJ was 64.89 and 61.58 respectively in normal healthy subjects.

\section{Discussion}

A significant reduction in IAUC of NH as compared to glucose was observed in subjects with IGT as well as normal healthy subjects suggesting that honey has no adverse effect on glycemic response and well tolerated by subjects with IGT. In this study among all the varieties of food preparation when tested in subjects with IGT as well as normal healthy subjects it was observed that nutribar made with honey had lowest GI (32.66 \& 32.44). This finding is supported by a study which reported that honey has lower glycemic index compared to many other carbohydrates (Abdulrhman M et al; 2009). According to the international table of glycemic index, honey has a GI value ranging between 32 and 87. This range is larger than can be accounted for by interlaboratory variation and probably represents real differences between honeys (Wolever TMS et al; 2008).

Nutribar made with honey was found to have lowest values for IAUC $(104.25,57.08)$ in subjects with IGT and normal healthy subjects with a reduction of $(67.34 \%, 67.55 \%)$ in IAUC compared to that of glucose. These results suggest and support the statement by Katsilambros et al. 1988 that honey could be better than products made with cane sugar, which is a common sweetener in used. 


\section{Conclusion}

Our findings indicate that honey may be used as a sweetener by normal as well as subjects with impaired glucose tolerance and also it could be incorporated in sweets as it has not shown any adverse effect on glycemic status.

\section{References}

[1] [ANON] (1995) Swiss food manual, Chapter 23 A, Honey. Eidgenössische Druck

[2] Abdulrhman M, El-Hefnawy M, Hussein R, et al. The glycemic and peak incremental indices of honey, sucrose and glucose in patients with type 1 diabetes mellitus: effects on C-peptide lev-el—a pilot study. Acta Diabetol. 2009; [Epub ahead of print].

[3] Bogdanov, S; Bieri, K; Figar, M: Figueiredo, V; Iff, D; Kanzig, A; Stockli, H; Zurcher, K (1995) Kapitel 23 Bienenprodukte: 23A Honig. Schweiz. Lebensmittelbuch (11).

[4] Brand JC, Nicholson PL, Thorburn AW, Truswell AS: Food processing and the glycemic index. Am J Clin Nutr 1985, 42: 11921196.

[5] Foster-Powell K, Holt SH, Brand-Miller JC. International table of glycemic index and glycemic load values: 2002. Am J Clin Nutr. 2002; 76:5-56. [PubMed]

[6] Gannon MC, Nuttall FQ, Westphal SA, Neil BJ, Seaquist ER: Effects of doseingested glucose on plasma metabolite and hormone responses in type II diabetic subjects. Diabetes Care 1989: 12:544-552.

[7] Ghosh, A.K. and M.P. Agrawal, 1983. Gur grading based on physical and chemical constituants. Maharastra sugar, 8(12): 39-43.

[8] Gibaldi, M. and D. Perrier, 1982. Pharmacokinetics. $2^{\text {nd }}$ Rev. Ed. Marcel Dekker, New York.

[9] Gopalan C, Rama Sastri BV, Balasubramanian SC. nutritive Value of Indian Foods. Hyderabad: national Institute of nutrition, Indian Council of Medical Research; 2004

[10] Hubrich, RD and O’Brien Nabors L. (2006) Glycemic response [online]. Retrieved April 13, 2010. From htt p: //www.foodproductdesign.com/ articles/2006/07/glycemic-response.aspx.

[11] Jenkins DJ, Wolever TM, Taylor RH, Barker H, Fielden H, Baldwin JM: Bowling AC, New HC, Jenkins AL, GoffDV: Glycemic index of food: a Physiological basis for Carbohydrate exchange. Am J Clin 34:362-366, 1981.

[12] KATSILAMBROS, N. L., PHILIPPIDES, P., TOUliATOU, A., GEORGAKOPOULOS, K., KOFOTZOUL, L., FRANGAKI, D., SISKOUDIS, P., MARANGOS, M. \& SFIKAKIS, P. (1988) Metabolic effects of honey (alone or combined with other foods) in type II diabetics, Acta Diabetologica Latina, 25: 197-203.

[13] Lipp, J; Zander, E; Koch, A (1994) Der Honig. Eugen Ulmer Stuttgart.

[14] WHITE, J W (1975) Composition of honey., In Crane, E (ed.) Honey. Comprehensive survey, Heinemann Edition; London; pp 157206.

[15] Wolever TMS, Boume GH (eds) (1990): The glycemic index. Aspects of some Vitamins, minerals and enzymes in health and diseases. World Review Nutr Diet 62, 120-185.

[16] Wolever TMS, Brand Miller J, Robert SD et al. measuring the glycemic index of foods: interlaboratory study. Am J Clin Nutr 2008; $87: 247$ S-57S. 